\title{
Bazı Kaba Yemlere Farklı Seviyelerde İlave Edilen Söğüt Ağacı (Salix Alba) Yaprağının in Vitro Sindirim ve Metan Oluşumu Üzerine Etkisi**
}

\author{
Ahmet ORUÇ ${ }^{1}$, Mehmet AVCl ${ }^{2 *}$ \\ ${ }^{1}$ Harran Üniversitesi, Sağlık Bilimleri Enstitüsü, Şanlıurfa, Türkiye. \\ ${ }^{2}$ Harran Üniversitesi, Veteriner Fakültesi, Hayvan Besleme ve Beslenme Hastalıkları Anabilim Dalı, Şanlıurfa, Türkiye.
}

Geliş Tarihi: 14.03.2018

Kabul Tarihi: 26.05.2018

\begin{abstract}
Özet: Bu araştırma, ruminant beslenmesinde yaygın olarak kullanılan buğday samanı, yonca kuru otu ve mısır silajına farklı oranlarda (\% 0, \% 10, \% 25, \% 50, \% 75 ve \% 100) eklenilen söğüt ağacı (Salix alba) yaprağının (SAY) in vitro metan gazı oluşumuna etkisini belirlemek amacıyla yapılmıştır. Farklı oranlarda SAY eklenmiş deneme yemleri in vitro gaz tekniği ile 24 saatlik inkubasyona bırakılmıştır. In vitro gaz üretim tekniği ile 24 saat içerisinde meydana gelen gaz bilgisayar destekli metan gazı ölçüm cihazına özel bir düzenekle enjekte edilerek metan gazı miktarları ölçülmüştür. SAY'da kuru maddede 105 $\mathrm{g} / \mathrm{kg}$ seviyesinde kondanse tanen içeriği belirlenmiştir. En düşük metan üretimi buğday samanına \% 50 ve 75 , yonca kuru otuna ve mısır silajına \% 75 seviyelerinde SAY ilave edilen gruplarda elde edilmiştir $(\mathrm{P}<0.05)$. En düşük amonyak azot değeri, yonca kuru otuna \% 50 ve \% 75 seviyelerinde SAY eklenen gruplarda saptanmıştır $(P<0.001)$. Ancak buğday samanına eklenen SAY amonyak azot değerini yükseltmiştir $(\mathrm{P}<0.01)$. Sonuç olarak $S A Y^{\prime} n ı n$ kaba yemlere eklenmesi, in vitro denemelerinde metan gazı oluşumunu düşürmüştür. SAY ilavesi metabolik enerji (ME) değerleri ile in vitro organik madde sindirilme derecesini (IVOMS) buğday samanında artırırken, yonca kuru otu ve mısır silajında düşürmüştür. Ayrıca SAY'nın hayvan performansı üzerindeki etkisinin ortaya konulabilmesi için in vivo çalışmalara ihtiyaç vardır.
\end{abstract}

Anahtar Kelimeler: Söğ̈̈t ağacı yaprağı, Metan, in vitro sindirilebilirlik.

The Effect of Willow Tree (Salix Alba) Leafs Added at Different Levels to Some Roughages on In Vitro Digestibility and

Methane Production

Abstract: This study was carried out to investigate the effect of willow tree leafs (Salix alba) added at different levels ( $0 \%$, $10 \%, 25 \%, 50 \%, 75 \%$ and $100 \%$ ) to grass forage, wheat straw, alfalfa forage and maize silage on the in vitro methane production. Methane production after $24 \mathrm{~h}$ incubation of the roughages were measured by injection of the produced gas samples into a special apparatus connected to computer. Condensed tannin content of willow tree leafs was determined as $105 \mathrm{~g} / \mathrm{kg}$ dry matter. The lowest methane production was determined in the groups of wheat straw added with 50 and $75 \%$ willow tree leafs as well as in the groups of alfa alfa hay and corn silage added with $75 \%$ willow tree leafs $(P<0.05)$. The lowest ammonia nitrogen level was observed for alfalfa forage in the treatment group containing 50 and $75 \%$ willow tree leafs $(P<0.001)$. However addition of willow tree leaves to wheat straw increased the ammonia nitrogen value in all treatment groups compared to control group $(P<0,01)$. As a conclusion addition of the willow tree leaf to roughages decreased in vitro methane production. Metabolic energy value and in vitro dry matter digestibility of wheat straw were increased while these values were decreased in alfa alfa roughage and corn silage by addition of willow tree leaf. Further in vivo studies are required in order to determine the effect of willow tree leaf addition on animal performance.

Keywords: Willow leaf, Methane, In vitro digestibility.

\section{Giriş}

Yemde bulunan toplam enerjinin yaklaşık $\% 12$ 'si ruminal fermantasyon sırasında metana $\left(\mathrm{CH}_{4}\right)$ çevrilerek ruktus yoluyla doğaya salınır (Thornton ve Owens, 1981). Hayvansal üretimin önemli bir sektör haline gelmesi ile birlikte sera gazlarının atmosferdeki miktarında ciddi artışlar gözlemlenmiştir (Houghton ve ark., 1992). Başta ruminantlar olmak üzere bazı hayvanlarda sindirim sürecinde yan ürün olarak meydana çıkan metan, organik maddelerin bakteriler tarafından yıkılmasından da meydana gelmektedir. Rumendeki fermantasyonun yanı sıra gübre boşaltma ve depolama işlemleri de metanın en önemli kaynaklarıdır (Jarvis ve ark., 1995). Atmosfere salınan bir yıllık metan gazının \%16.4'ünün, ruminant hayvanlar ile hayvanların gübresinden meydana geldiği belirtilmektedir. Bu \%16.4'lük değer küresel ısınmaya sebep olan bütün sera gazlarının aşağı yukarı \%2.9'unu meydana getirmektedir (Johnson ve ark., 1992). Ruminantlarda meydana gelen metan gazının küresel ısınmaya olan etkisinin yanı sıra, rumende metabolize olan ve yemlerle alınan yem enerjisinin takriben \%12'si metan oluşumu nedeniyle 
kaybedilmektedir. Geçmiş zamanlarda bu enerji kaybını önlemek için rumendeki ortamı gram negatif (-) bakteriler lehine döndürerek metan gazı üretimini baskılayan iyonofor grubu antibiyotikler ruminant rasyonlarına ilave edilmiştir. Ancak Türkiye'de ve Avrupa Birliği ülkelerinde hayvan yemlerinde antibiyotik kullanımı yasak olduğundan iyonoforların metan gazı üretimini baskılamak için kullanılması mümkün olmamaktadır. Bu yüzden araştırmacılar rumen kaynaklı metan gazı üretimini ve dolayısıyla enerji kaybını önlemek için bitki ve bitkisel kaynaklı katkılar üzerinde çalışmalarını yoğunlaştırmışlardır. Bu doğrultuda bitki, bitki ekstrakları ve bitkilerden elde edilen esansiyel yağlar rumen mikrobiyal fermantasyonu ve besin maddeleri kullanım etkinliğini iyileştirmektedir (Busquet ve ark., 2005). Söğüt ağacı, söğütgiller (Salicaceae) familyasına bağlı söğüt (Salix) cinsi içerisinde yer alan bodur çalı veya uzun boylu ağaç halinde, çoğunlukla kışları yaprak döken odunsu ağaçlardır. Söğüt ağacının kabuklarından salisin adı verilen madde elde edilmekte, insan ve hayvanlar tarafından vücut içinde metabolize edilerek Aspirinin aktif maddesi olarak bilinen salisilik asit'e dönüştürülmektedir (Anonim, 2016). Türkiye'de yetişen söğüt ağaç türlerinin kurumuş dalların kabuğunda \%15 dolaylarında tanen bulunmakta olup kuvvet verici, yatıştırıcı, peklik yapıcı, antiromatizmal ve ateş düşürücü tesirlere sahiptir (Baytop, 1984). Ülkemizde bilhassa söğüt ve meşe ağaçlarında var olan tanenler hemostatik, peklik yapıcı ve astrenjan (doku ya da mukoza büzücü) tesirlerinin yanında, alkaloit bulunduran bitkiler ile zehirlenme olaylarında antidot maksadıyla kullanılmaktadır (Baytop, 1984; Radeleff, 1970; Şener ve Yıldırım, 2000).

$\mathrm{Bu}$ araştırma kapsamında, ruminant rasyonlarında çok kullanılan buğday samanı, yonca kuru otu ve mısır silajına farklı düzeylerde ilave edilen SAY'ın (Salix alba) in vitro organik madde sindirimi ve metan $\left(\mathrm{CH}_{4}\right)$ oluşumuna etkisi araştırılmıştır.

\section{Materyal ve Metot}

Çalışmada kullanılan yonca kuru otu, buğday samanı ile mısır silajı Harran Üniversitesi Hayvancılık Araştırma Ünitesinden temin edilmiştir. Çalışmadaki SAY, söğüt ağacının yeşil yapraklarından taze olarak temin edilmiştir. Taze söğüt yaprakları gölgede kurutularak öğütülmeye hazır hale getirilmiştir. Araştırmada, kullanılan buğday samanı, yonca kuru otu, mısır silajı ve söğüt yaprakları $1 \mathrm{~mm}$ 'lik eleklerden geçecek şekilde bitki öğütme değirmeninde öğütülmüştür. SAY ve test yemlerinin ham kül, ham protein, kuru madde analizleri AOAC (2005)'e, NDF (Neutral Detergant Fibre) ve ADF (Asit Detergant Fibre) analizleri Van Soest ve ark. (1991)'nın bildirdikleri yönteme göre yapılmıştır. SAY'nın kondanse tanen miktarının belirlenmesi Makkar ve ark. (1995) tarafından bildirilen metoda göre yapılmıştır. Yem maddelerinin (yonca kuru otu, buğday samanı ve mısır silajı) her birine katkısız (kontrol), \%10, \%25, \%50, \%75 ve \%100 düzeyinde SAY ilave edilmiş ve her seviye 4 tekerrürlü olarak yapılmıştır.

Araştırmada, Menke ve ark. (1988) tarafından bildirilen gaz üretim tekniği kullanıldı. Bu yöntemin temeli, yemlerin, rumen sıvısı ile 24 saatlik inkübasyonu sonucu oluşan gaz miktarının ölçülmesine dayanır. Elde edilen sonuçlar yem maddelerinin metabolik enerji (ME) ve in vitro organik madde sindirilebilirlik (IVOMS) düzeylerinin hesaplanmasında kullanılmıştır. Elde edilen gaz içerisindeki $\mathrm{CH}_{4}$ yüzdesi bilgisayara bağlı metan gazı ölçüm cihazı (Sensors Analysentechnik GmbH\&Co. KG, Berlin, Germany) yardımıyla belirlenmiştir. Enjektörlerde kalan rumen sıvısı ve yem karışımı 4 katlı tülbentten süzülerek $\mathrm{pH}$ değerleri okunmuş, bu numunelerde $\mathrm{NH}_{3}-\mathrm{N}$ analizlerinin yapılacağı zamana kadar derin dondurucuda eksi $20{ }^{\circ} \mathrm{C}^{\prime}$ de bekletilmiştir. Rumen sıvısının $\mathrm{NH}_{3}-\mathrm{N}$ değerleri Markham distilasyon yöntemi ile tespit edilmiştir (Markham, 1942).

Elde edilen değerlerin istatistiksel analizi SPSS 13.0 programında tek yönlü varyans (ANOVA) analizi ile yapıldı. Gruplar arasındaki farklılıkların önemi, Duncan çoklu karşılaştırma testiyle belirlendi (SPSS, 2004).

\section{Bulgular}

Çalışmada kullanılan SAY'daki tanen içeriğinin $105 \mathrm{~g} / \mathrm{kg}$ KM olduğu tespit edilmiştir. Buğday samanı, yonca kuru otu ve mısır silajına farklı oranlarda $\mathrm{SAY}$ ilave edilmesinin in vitro gaz üretimi, iVOMS, $\mathrm{ME}, \mathrm{CO}_{2}, \mathrm{CH}_{4}, \mathrm{pH}$ ve $\mathrm{NH}_{3}-\mathrm{N}$ düzeylerine etkileri tablo1, 2 ve 3'de verilmiştir.

\section{Tartışma ve Sonuç}

Bitkilerin, parazitlere karşı kendilerini korumak amacıyla sentezledikleri bioaktif metabolitler arasında flavanoidler, alkaloidler, karotenoidler, tanenler, fenolik bileşikler, eterik yağlar ve saponinler bulunur (Kaçar, 2008). Bitkilerin yapraklarında bulunan tanenlerin mayalar, küfler, bazı virüsler ve bakteriler üzerinde antimikrobiyel etkileri bulunmaktadır. Tanenlerin antimikrobiyel etkisi; mikroorganizmaların enzimler veya 
substratlarıyla farklı bileşikler teşkil edip, hücre zarlarında toksik etki yaparak bakteriler üzerinde bakterisid ve bakteriostatik etki oluşturmasıyla gerçekleşir (Akiyama ve ark., 2001; Scalbert, 1991). Meyve ve sebzelerde var olan fenolik bileşiklerin antioksidan tesirleri bilhassa redoks niteliklerinden ve iyi bir hidrojen vericisi olmalarından kaynaklanmaktadır (Banerjee ve ark., 2005; Başer, 2002). Yapılmış in vitro ve in vivo çalışmalarda, bahsedilen metabolitleri yoğun olarak bulunduran bir takım bitki ekstraktlarının rumende amonyak, laktik asit ve metan oluşumunu düşürdüğü, asetatın propiyonata oranını düşürerek rumende bulunan UYA (uçucu yağ asitleri) profilini hayvanın lehine dönüştürdüğü ortaya konulmuştur (Cardozo ve ark., 2004; Castillejos ve ark., 2008). Rumende, karbon içeren ve mikrobiyal fermantasyon sonucu şekillenen bütirik ve asetik asitin mikroorganizmalar tarafından üretimi sırasında, hidrojen meydana gelmektedir. Rumende oluşan hidrojen ise metanojenik mikroorganizmalarca $\mathrm{CO}_{2}$ ile birleştirilerek $\mathrm{CH}_{4}$ 'a dönüştürülmektedir (Houghton ve ark., 1992). Bütirik ve asetik asit üretilmesinden farklı olarak, propiyonik asidin üretilmesi sırasında ortamda bulunan hidrojen iyonları kullanılmaktadır (Newbold ve ark., 1988; Yost ve ark., 1977). Bu nedenle UYA profilinin propiyonik asit lehine dönüştürülmesi, yemden alınan enerjinin ruminantlar tarafından daha fazla kullanılmasını sağlamaktadır. Tanenler, proteinlerle ve diğer makro moleküllerle beraber çaprazlama bağlar oluşturabilmektedir (Hagerman ve ark., 1992; Kamalak ve ark., 2005; Silanikove ve ark., 2001). Tanenler, selülozu parçalayan mikroorganizmalar üzerinde baskılayıcı etki oluşturarak asetatın meydana gelişini düşürürler. Böylece metan gazının oluşumu için gerekli olan hidrojen iyonları ile karbondioksitin üretimini sınırlamaktadırlar (Patra ve Saxena, 2009; Waghorn, 2008). Yapılan bu çalışmada kullanılan SAY'ndaki tanen içeriğinin 105 $\mathrm{g} / \mathrm{kg}$ KM olduğu tespit edilmiştir. Çalışmada kullanılan SAY'nın içerdiği tanen seviyesi metan üretimini düşürebilecek seviyededir. Araştırmada metan gazı üretimi, buğday samanı, yonca kuru otu ve mısır silajına ilave edilen SAY düzeyine bağlı olarak \%27.70 ile 14.51 arasında değişmiştir. Yonca kuru otu ve mısır silajına yapılan SAY katkı düzeyine paralel olarak $\mathrm{CH}_{4}$ gazının oluşumu önemli düzeyde azalırken $(\mathrm{P}<0.001)$ buğday samanı grubunda $\mathrm{CH}_{4}$ gazı oluşumundaki düşüş $\mathrm{P}<0.05$ seviyesinde önemli bulunmuştur. $\mathrm{CO}_{2}$ ve $\mathrm{CH}_{4}$ gazları, rumende bulunan yemlerin fermantasyonu neticesinde oluşan hidrojen $(\mathrm{H}+)$ iyonu ve UYA'lerini kullanan metanojenik mikroorganizmalar tarafından meydana getirilmektedir (Benchaar ve Greathead, 2011; Busquet ve ark. 2006). Rumende bulunan metanojenik bakteriler, SAY'ndaki tanenin antimikrobiyel özelliklerinden dolayı sayıca azalma göstermektedirler. Böylece rumende $\mathrm{CH}_{4}$ gazın meydana gelişi azalmaktadır (Benchaar ve Greathead, 2011). Benzer şekilde Canbolat ve ark. (2010) rumen içeriğine $800 \mathrm{mg} /$ /t kekik yağı, Evans ve Martin (2000) ise $400 \mu \mathrm{g} / \mathrm{ml}$ seviyesinde timol ilavesinin $\mathrm{CH}_{4}$ gazı oluşumunu baskıladığını bildirmişlerdir. Agarwal ve ark. (2009) $\mathrm{CH}_{4}$ gazı oluşumu üzerindeki etkisini belirlemek için 0.33, 1 ve $2 \mu \mathrm{l} / \mathrm{ml}$ nane yağının rumen sıvısına ilavesinin $\mathrm{CH}_{4}$ gaz oluşumunu \%19.9, \%46.0 ve \%75.6 seviyelere düştüğünü bildirmişlerdir $(\mathrm{P}<0.01)$. Busquet ve ark. (2006) da rumen sıvisına sırasıyla; 0, 3, 30, 300 ve $3000 \mathrm{mg} / \mathrm{lt}$ düzeyinde kekik yağı ilavesinin $\mathrm{CH}_{4}$ gazı oluşumunu düşürdügünü saptamışlardır. Canbolat ve ark. (2011) rumen içeriğine kekik yağı ile nane yağı eklemesinin $\mathrm{CO}_{2}$ ve $\mathrm{CH}_{4}$ gazlarını önemli oranda azalttığını bildirmişlerdir. Macheboeuf ve ark. (2008) rumen içeriğine $246 \mathrm{mg} / \mathrm{l}$ tarçın yağı eklenmesinin $\mathrm{CH}_{4}$ gaz üretimini $\% 13$ seviyesinde azalttığını bildirmektedirler. Chaves ve ark. (2008), rumen içeriğine 400 ile $500 \mathrm{mg} / \mathrm{l}$ düzeyinde karanfil yağı ilave etmişler ve bu düzeyde ilave edilen karanfil yağın $\mathrm{CH}_{4}$ gazı oluşumunu düşürdüğünü (\%30 ile \%35) belirlemişlerdir. Bu araştırmada, daha önce yapılmış çalışmalar gibi metan gazı oluşumunu düşürdüğü gözlenmiş olup, bunun nedeni, SAY'ındaki tanenin, rumende bulunan metanojenik bakterileri baskılayarak metan gazı üretimini azalttığı düşünülmektedir.

Buğday samanı, yonca kuru otu ve mısır silajına ilave edilen SAY'nın IVOMS üzerine olan etkisi bu çalışmada saptanmış olup değerler \%45.93 ile \%63.01 arasında değişmiştir. Buğday samanı, yonca kuru otu ve mısır silajına ilave edilen sögüt ağacı yapraklarının iVOMS üzerine olan etkileri ile ilgili sonuçlara bakıldığında, iVOMS değerlerinin buğday samanında önemli derecede artış gösterdiği, yonca kuru otu ve mısır silajında ise azaldığı tespit edilmiştir $(P<0.001)$. Sonuçlar buğday samanına ilave edilen SAY'nın, ME seviyesine etkisi bakımından değerlendirildiğinde $M E$ değerinin artığı, ancak yonca kuru otu ve mısır silajının ise $\mathrm{ME}$ değerlerini düşürdüğü belirlenmiştir $(P<0.001)$. Yonca kuru otu, mısır silajı ve buğday samanına ilave edilen söğüt yapraklarının bu yem hammaddelerinin kuru madde ham protein miktarını belirgin bir şekilde artırdığı belirlenmiştir $(P<0.001)$. Bu artışın sebebi olarak SAY'nın ham protein oranının, yonca kuru otu, mısır silajı ve buğday samanından yüksek olmasından kaynaklandığı söylenebilir. Araştırmada, sögüt ağacı yapraklarının in vitro gaz üretim miktarını, samanda belirgin bir şekilde artırırken, yonca kuru otu ve mısır silajında azalttığı 
gözlenmiştir $(P<0.001)$. Söğüt ağacı yapraklarının, yonca kuru otu ve mısır silajında in vitro gaz üretimini azaltmasını, tanenlerin ve aktif bileşenlerinin antimikrobiyel etkisi nedeni ile (Benchaar ve ark., 2007; Calsamiglia ve ark., 2007; Evans ve Martin, 2000), rumen mikroorganizmalarının miktarında ve akvitelerinde sınırlamaya (Newbold ve ark., 2004) ve bakteriler üzerinde antimikrobiyel etkide bulunmasına bağlanılabilir. Yapılmış birçok araştırmada da (Agarwal ve ark., 2009; Kamalak ev ark., 2011) esansiyel yağların (portakal, kekik, timol, nane) invitro gaz üretimini düşürdüğü bildirilmektedir.

Rumen sıvısının pH seviyesi ise tüm kaba yem grupları dikkate alındığında 6.93 ile 7.04 aralığında değişiklik göstermiş olup, SAY katkı seviyeleri arasındaki farklılıklar önemli bulunmuştur $(P<0.001)$. En yüksek $\mathrm{pH}$ değerleri kontrol gruplarında saptanmıştır. Yonca kuru otu ve buğday samanı SAY katkı seviyesindeki artışa paralel şekilde $\mathrm{pH}^{\prime}$ daki düşüş, rumende alkali ortamın kaynağını meydana getiren protein yıkılımının az olması ile açıklanabilir. Mısır silajına SAY'ın katkı seviyesine paralel olarak pH değeri yükselmiştir. Çalışmada belirlenen $\mathrm{pH}$ seviyeleri değişik esansiyel yağlarla çalışan Busquet ve ark. (2005), Calsamiglia ve ark. (2007) ile Canbolat ve ark. (2010)'nın bulgularıla benzer bulunmuştur. $\mathrm{P}^{\mathrm{H}}$ bulguları portakal yağı, nane yağı ve kekik yağıyla çalışmalar yapan Canbolat ve ark. (2011)'nın bildirdikleri sonuçlar ile de uyumludur.

Tablo 1. Buğday samanına farklı oranlarda SAY (Salix Alba) ilavesinin ham besin madde (\% KM) içerikleri, in vitro gaz oluşumu ve amonyak azotu üzerine etkisi.

\begin{tabular}{|c|c|c|c|c|c|c|c|c|}
\hline Parametre & Kontrol & \%10 SAY & \%25 SAY & $\% 50$ SAY & \%75 SAY & $\% 100$ SAY & SEM & $\mathbf{P}$ \\
\hline Gaz ml/g KM & $155.29^{\mathrm{e}}$ & $161.10^{\mathrm{de}}$ & $165.21^{d}$ & $176.20^{c}$ & $189.89^{b}$ & $197.41^{\mathrm{a}}$ & 3.31 & $* *$ \\
\hline $\mathrm{CH}_{4} \%$ & $17.00^{\mathrm{a}}$ & $16.76^{\mathrm{a}}$ & $16.00^{\mathrm{a}}$ & $14.64^{b}$ & $14.51^{b}$ & $14.11^{\mathrm{b}}$ & 0.31 & $*$ \\
\hline $\mathrm{NH}_{3}-\mathrm{N} \mathrm{mg/dl}$ & $19.11^{b}$ & $22.56^{\mathrm{a}}$ & $24.45^{a}$ & $24.99^{\mathrm{a}}$ & $25.41^{\mathrm{a}}$ & $25.60^{\mathrm{a}}$ & 0.63 & $* *$ \\
\hline pH & $7.03^{a}$ & $6.98^{c}$ & $7.00^{b}$ & $6.99^{b c}$ & $6.99 b^{c}$ & $6.97^{c}$ & 0.01 & $* * *$ \\
\hline KM\% & $95.85^{a}$ & $95.75^{b}$ & $95.61^{\mathrm{c}}$ & $95.36^{d}$ & $95.12^{\mathrm{e}}$ & $94.87^{f}$ & 0.07 & $* * *$ \\
\hline IVOMS \%КM & $45.93^{c}$ & $46.18^{c}$ & $49.14^{b}$ & $49.23^{b}$ & $56.24^{a}$ & $56.19^{a}$ & 0.90 & $* * *$ \\
\hline ME MJ/kg KM & $6.83^{d}$ & $6.92^{d}$ & $7.33^{c}$ & $7.50^{c}$ & $8.74^{b}$ & $8.95^{a}$ & 0.18 & $* * *$ \\
\hline HP \%КM & $3.59^{f}$ & $4.78^{e}$ & $6.57^{d}$ & $9.54^{c}$ & $12.2^{\mathrm{b}}$ & $15.49^{\mathrm{a}}$ & 0.88 & $* * *$ \\
\hline ADF \%KM & $48.33^{a}$ & $46.29^{b}$ & $43.24^{c}$ & $38.15^{d}$ & $33.05^{e}$ & $27.96^{f}$ & 1.51 & $* * *$ \\
\hline NDF \%KM & $77.37^{\mathrm{a}}$ & $72.96^{\mathrm{b}}$ & $66.34^{\mathrm{C}}$ & $55.31^{d}$ & $44.27^{e}$ & $33.24^{f}$ & 3.27 & $* * *$ \\
\hline НК \%КМ & $12.18^{\mathrm{a}}$ & $11.88^{\mathrm{b}}$ & $11.42^{\mathrm{C}}$ & $10.67^{d}$ & $9.91^{\mathrm{e}}$ & $9.15^{f}$ & 0.23 & $* * *$ \\
\hline
\end{tabular}

Aynı satırda farklı harf taşıyan ortalama değerler arasındaki fark istatistik bakımdan önemlidir, HP: Ham protein, KM: Kuru madde, SAY: Söğüt ağacı yaprağı, (-): P>0.05, (*): P<0.05, (**): $\mathrm{P}<0.01,\left({ }^{* * *}\right)$ : $\mathrm{P}<0.001$.

Tablo 2. Yonca kuru otuna farklı seviyelerde SAY (Salix Alba) ilavesinin in vitro gaz oluşumu ve amonyak azotu üzerine etkisi.

\begin{tabular}{|c|c|c|c|c|c|c|c|c|}
\hline Parametre & Kontrol & \%10 SAY & \%25 SAY & \%50 SAY & \%75 SAY & \%100 SAY & SEM & $\mathbf{P}$ \\
\hline Gaz ml/g KM & $238.42^{\mathrm{a}}$ & $212.36^{b}$ & $196.61^{\text {cd }}$ & $190.24^{d}$ & $202.11^{c}$ & $189.89^{d}$ & 3.67 & $* * *$ \\
\hline $\mathrm{CH}_{4} \%$ & $27.70^{\mathrm{a}}$ & $21.76^{b}$ & $21.15^{b}$ & $17.00^{c}$ & $15.49^{d}$ & $14.11^{d}$ & 0.98 & $* * *$ \\
\hline $\mathrm{NH}_{3}-\mathrm{N} \mathrm{mg/dl}$ & $35.21^{\mathrm{a}}$ & $32.70^{\mathrm{a}}$ & $32.74 a$ & $27.06^{b}$ & $27.95^{b}$ & $22.56^{\mathrm{c}}$ & 0.98 & $* * *$ \\
\hline pH & $7.04^{a}$ & $7.01^{b}$ & $7.01^{b}$ & $7.00^{b}$ & $6.99^{b}$ & $6.97^{c}$ & 0.01 & $* * *$ \\
\hline KM \% & $92.63^{f}$ & $92.85^{e}$ & $93.19^{d}$ & $93.75^{c}$ & $94.31^{b}$ & $94.80^{\mathrm{a}}$ & 0.17 & $* * *$ \\
\hline IVOMS \%КM & $63.84^{\mathrm{a}}$ & $59.09^{b}$ & $56.57^{\text {cd }}$ & $55.71^{d}$ & $58.09^{b c}$ & $56.19^{d}$ & 0.61 & $* * *$ \\
\hline ME MJ/kg KM & $9.95^{a}$ & $9.21^{b}$ & $9.19^{b c}$ & $8.95^{\text {bd }}$ & $8.86^{d}$ & $8.78^{d}$ & 0.09 & $* * *$ \\
\hline HP \%КM & $12.99^{f}$ & $13.24^{\mathrm{e}}$ & $13.62^{d}$ & $14.24^{c}$ & $14.87^{b}$ & $15.49^{\mathrm{a}}$ & 0.19 & $* * *$ \\
\hline ADF \%KM & $34.74^{\mathrm{a}}$ & $34.06^{\mathrm{b}}$ & $33.05^{c}$ & $31.35^{d}$ & $29.66^{\mathrm{e}}$ & $27.96^{f}$ & 0.50 & $* * *$ \\
\hline NDF \%KM & $38.14^{a}$ & $37.65^{b}$ & $36.92^{c}$ & $35.69^{d}$ & $34.47^{e}$ & $33.24^{f}$ & 0.36 & $* * *$ \\
\hline НК \%КМ & $9.55^{a}$ & $9.51^{b}$ & $9.45^{c}$ & $9.35^{d}$ & $9.25^{e}$ & $9.15^{f}$ & 0.30 & $* * *$ \\
\hline
\end{tabular}

Aynı satırda farklı harf taşıyan ortalama değerler arasındaki fark istatistik bakımdan önemlidir, HP: Ham protein, KM: Kuru madde, SAY: Söğüt ağacı yaprağı, $(* * *): P<0.001$.

Tablo 3. Mısır silajına farklı seviyelerde SAY (Salix Alba) ilavesinin in vitro gaz oluşumu ve amonyak azotu üzerine etkisi.

\begin{tabular}{|c|c|c|c|c|c|c|c|c|}
\hline Parametre & Kontrol & \%10 SAY & $\% 25$ SAY & $\% 50$ SAY & \%75 SAY & $\% 100$ SAY & SEM & $\mathbf{P}$ \\
\hline Gaz ml/g KM & $248.92^{a}$ & $238.35^{b}$ & $210.90^{c}$ & $211.64^{c}$ & $200.05^{d}$ & $189.89^{\mathrm{e}}$ & 4.40 & $* * *$ \\
\hline $\mathrm{CH}_{4} \%$ & $27.24^{\mathrm{a}}$ & $23.01^{b}$ & $22.44^{\mathrm{b}}$ & $20.67^{c}$ & $16.69^{d}$ & $14.11^{\mathrm{e}}$ & 0.92 & $* * *$ \\
\hline $\mathrm{NH}_{3}-\mathrm{N} \mathrm{mg/dl}$ & $30.44^{a}$ & $28.72^{\mathrm{a}}$ & $28.09^{a}$ & $27.17^{\mathrm{a}}$ & $26.47^{a}$ & $22.56^{\mathrm{b}}$ & 0.69 & $* * *$ \\
\hline $\mathrm{pH}$ & $6.98^{a}$ & $6.93^{c}$ & $6.95^{b c}$ & $6.98^{\mathrm{a}}$ & $6.96^{\mathrm{ab}}$ & $6.97^{\mathrm{ab}}$ & 0.01 & $* * *$ \\
\hline KM \% & $92.90^{f}$ & $93.01^{\mathrm{e}}$ & $93.39^{d}$ & $93.89^{c}$ & $94.38^{b}$ & $94.87^{a}$ & 0.08 & $* * *$ \\
\hline IVOMS \% KM & $63.01^{a}$ & $60.72^{b}$ & $56.86^{\mathrm{cd}}$ & $58.01^{\mathrm{c}}$ & $56.98^{\mathrm{cd}}$ & $56.19^{d}$ & 0.53 & $* * *$ \\
\hline ADF \% KM & $32.50^{\mathrm{a}}$ & $32.05^{b}$ & $31.37^{c}$ & $30.23^{d}$ & $29.10^{\mathrm{e}}$ & $27.96^{f}$ & 0.34 & $* * *$ \\
\hline NDF \% KM & $57.61^{a}$ & $55.17^{b}$ & $51.52^{c}$ & $43.43^{d}$ & $39.33^{\mathrm{e}}$ & $33.24^{f}$ & 1.81 & $* * *$ \\
\hline HK \% KM & $6.90^{f}$ & $7.13^{\mathrm{e}}$ & $7.46^{d}$ & $8.03^{c}$ & $8.59^{b}$ & $9.15^{a}$ & 0.17 & $* * *$ \\
\hline
\end{tabular}

Aynı satırda farklı harf taşıyan ortalama değerler arasındaki fark istatistik bakımdan önemlidir, HP: Ham protein, KM: Kuru madde, SAY: Söğüt ağacı yaprağı, $(* * *): P<0.001$. 
Bütün gruplar dikkate alındığında rumen içeriğ $\mathrm{NH}_{3}-\mathrm{N}$ miktarı 19.11-35.21 mg/dl aralarında değişmiştir. En yüksek $\mathrm{NH}_{3}-\mathrm{N} \mathrm{SAY}$ içermeyen yonca ve mısır silajı gruplarında, en düşüğü ise 19.11 $\mathrm{mg} / \mathrm{dl}$ ile söğüt yaprağı bulunmayan buğday samanı grubunda saptanmıştır. Yonca kuru otu ve mısır silajı gruplarındaki rumen içeriği $\mathrm{NH}_{3}-\mathrm{N}$ seviyesindeki azalma, tanenlerin öncelikle rumende bulunan mikroorganizmalarının etkinliğini azaltması ile aminoasitlerin deaminasyonunun önlenmesinden kaynaklanmaktadır (Mcintosh ve ark., 2003). Yapılan bir araştırmada bitkilerde var olan tanenlerin doğru dozda kullanılması durumunda rumende parçalanan protein miktarını düşürerek, ince bağırsağa geçen by pass protein miktarlarını yükselttiği bildirilmiştir (Carulla ve ark., 2005). Ruminantlarda $\mathrm{NH}_{3}-\mathrm{N}$ şeklinde azot kaybının önlenmesi, verim kayıpları ve atmosfere $\mathrm{CH}_{4}$ ile $\mathrm{NH}_{3}-\mathrm{N}$ gazları salınımlarını düşürerek çevre kirliğini önleyebileceği bildirilmektedir (Calsamiglia ve ark., 2007; Tamminga, 1996). Wallace ve ark. (2002), rumende $\mathrm{NH}_{3}-\mathrm{N}$ oluşumunun düşmesinin beslenme açısından faydalı olduğunu bildirmişlerdir. Busquet ve ark. (2006) da rumen içeriğine sırasıyla; 0, 3, 30, 300 ve $3000 \mathrm{mg} / \mathrm{l}$ düzeylerinde kekik yağı ilavesinin $\mathrm{NH}_{3}-\mathrm{N}$ düzeyini \%30-50 aralarında düşürdüğünü tespit etmişlerdir. Agarwal ve ark. (2009) rumen içeriğine eklenen nane yağının amonyak seviyesini düşürdüğünü bildirmişlerdir. Canbolat ve ark. (2011)'ı rumen içeriğine $400 \mathrm{mg} / \mathrm{l}$ kekik yağı, portakal yağı ve nane yağı ilave edilmesinin $\mathrm{NH}_{3}$ N'nu kontrol grubuna göre önemli düzeyde düşürdüğünü saptamışlardır. Bu çalışmada $\mathrm{NH}_{3}-\mathrm{N}$ parametresi ile ilgili olarak ortaya çıkan sonuçlar yukarıda sayılan çalışma sonuçlarıyla uyumludur. Bir başka çalışmada Hristov ve ark. (2008) kısa süre zarfında in vitro inkübasyon denemelerinde, adaçayı ve biberiye yağlarının 10 ve $100 \mathrm{mg} / \mathrm{l}$ dozlarının ruminal $\mathrm{NH}_{3}-\mathrm{N}$ konsantrasyonu üzerine istatistikî açıdan etkilerinin bulunmadığını bildirmişlerdir. Bu araştırmada saptanan $\mathrm{NH}_{3}-\mathrm{N}$ düzeyleri, kekik yağının farklı dozları $(0,3,30,300$ ve $3000 \mathrm{mg} / \mathrm{l}$ rumen sıvısı) ile çalışan Busquet ve ark. (2005)'nın bulgularından yüksek, timolun farklı dozları $(0,5,50$, 500 ve 5000 mg/l rumen sıvısı) ile çalışan Castillejos ve ark. (2006)'nın bulgularıyla benzerdir.

$\mathrm{Bu}$ araştırma sonuçlarına göre, SAY'nın kaba yemlere eklenmesi ile $\mathrm{NH}_{3}-\mathrm{N}, \mathrm{CH}_{4}$, iVOMS ve $\mathrm{ME}$ parametrelerinde önemli gelişmeler görülmüştür. Ruminant beslemede küresel ısınmaya sebep olan sera gazlarının azaltılması hem çevre hem de ruminantlarda $\mathrm{CH}_{4}$ 'dan kaynaklanan enerji kaybının azaltılması günümüzde önem arz eden konuların başında gelmektedir. Ruminanat kaynaklı sera gazı oluşumunun düşürülmesi, ruktusla $\mathrm{CH}_{4}$ kaynaklı enerji kaybının azaltılması ve rumende $\mathrm{NH}_{3}-\mathrm{N}$ oluşumunun düşürülmesi ruminant hayvanların beslenmesi açısından faydalı olacağı düşüncesiyle SAYnın ruminant rasyonlarında kullanılması önemli bir fayda sağlayacaktır. Fakat rasyonlara eklenecek SAY'nın hayvansal üretim ve yem tüketimi üzerine etkisinin bütünüyle ortaya konulabilmesi için in vivo çalışmalara ihtiyaç duyulduğu sonucuna varılmıştır.

\section{Kaynaklar}

Agarwal N, Shekhar C, Kumar R, Chaudhary LC, Karma DN, 2009: Effect of peppermint (Mentha piperita) oil on in vitro methanogenesis and fermentation of feed with buffalo rumen liquor. Anim Feed Sci Technol, 148, 321-327.

Akiyama H, Fujii K, Yamasaki O, Oono T, 2001: Iwatsuki K. Antibacterial Action of Several Tannins Against Staphylococcus aureus. Journal of Antimicrobial Chemotherapy, 48, 487-491.

Anonim, 20016: https://tr.wikipedia.org/wiki/Söğüt, Erişim Tarihi; 09.05.2016.

AOAC, 2005: Official Methods of Analysis of AOAC international, 18th ed. Association of Official Analytical Chemists, Washington DC, USA.

Banerjee A, Dasgupta N, De B, 2005: In vitro study of antioxidant activity of syzgium cumini fruit. Food Chemistry, 90, 727-733.

Başer CHK, 2002: Fonksiyonel gıdalar ve nutrasötikler. 14. Bitkisel ilaç hammaddeleri toplantısı, Bildiriler (2931 Mayıs), Eskişehir.

Baytop T, 1984: Türkiye' de Bitkilerle Tedavi (Geçmişte ve Bugün). İstanbul Üniversitesi Yayınları No:3255, Eczacılık Fakültesi No:40, 93, 167, 169, 195, 275, 327-330, 357, 382, 420.

Benchaar C, Greathead H, 2011: Essential oils and opportunities to mitigate enteric methane emissions from ruminants. Anim Feed Sci Technol, 166-167, 338-355.

Benchaar C, Petit HV, Berthiaume R, Ouellet DR, Chiquette J, Chouinard PY, 2007: Effects of essential oils on digestion, ruminal fermentation, rumen microbial populations, milk production, and milk composition in dairy cows fed alfalfa silage or corn silage. J Dairy Sci, 90, 886-897.

Busquet M, Calsamiglia S, Ferret A, Kamel C, 2006: Plant extracts affect in vitro rumen microbial fermentation. J Dairy Sci, 89, 761-771.

Busquet M, Calsamiglia S, Ferret A, Kamel C, 2005: Screening for the effects of natural plant extracts and secondary plant metabolites on rumen microbial fermentation in continuous culture. Anim. Feed Sci Technol, 123-124, 597-613.

Calsamiglia S, Busquet M, Cardozo PW, Castillejos L, Ferret A, 2007: Essential oils as modifiers of rumen microbial fermentation. J Dairy Sci, 90, 2580-2595. 
Canbolat Ö, Kalkan H, Karaman Ş, Filya I, 2011: Esansiyel yağların sindirim, rumen fermantasyonu ve mikrobiyal protein üretimi üzerine etkileri. Kafkas Univ Vet Fak Derg, 17(4): 557-565.

Canbolat Ö, Karaman Ş, Filya I, 2010: Farklı Kekik Yağı Dozlarının Yemlerin Sindirimi ve Rumen Fermantasyonu Üzerine Etkileri. Kafkas Univ Vet Fak Derg, 16(6): 933-939.

Cardozo PW, Calsamiglia S, Ferret A, Camel C, 2004: Effects of Natural Plant Extracts on Ruminal Protein Degration and Profiles in Fermentation Continuous Culture. J Anim Sci, 82, 3230-3236.

Carulla JE, Kreuzer M, Machmüller A, Hess HD, 2005: Supplementation of Acacia mearnsii tannins decreases methanogenesis and urinary nitrogen in forage-fed sheep. Aust J Agric Res, 56, 961-970.

Castillejos L, Calsamiglia S, Ferret A, 2006: Effect of essential oil active compounds on rumen microbial fermentation and nutrient flow in in vitro systems. $J$ Dairy Sci, 89, 2649-2658.

Castillejos L, Calsamiglia S, Martin-Tereso J, 2008: Ter Wijlen $\mathrm{H}$, In vitro evaluation of effects of essential oils at three doses on ruminal fermentation of high concentrate feedlot-type diets. Anim. Feed Sci Technol, 145, 259-270.

Chaves AV, He ML, Yang WZ, Hristov AN, McAllister TA, Benchaar C, 2008: Effects of essential oils on proteolytic, deaminative and methanogenic activities of mixed ruminal bacteria. Can J Anim Sci, 88, 117-122.

Evans JD, Martin SA, 2000: Effects of thymol on ruminal microorganisms. Curr Microbiol, 41, 336-340.

Hagerman EA, Robbins TC, Weerasuriya $\mathrm{Y}$, Wilson CT, Mcarthur C, 1992: Tannin chemistry in relation to digestion. Journal of Range Management, 45 (1): 57-62.

Houghton JT, Callander BA, Varney SK, 1992: Climate Change, The Supplementary Report to the IPCC Scientific Assessment, NY, USA: Cambridge University Press.

Hristov AN, Ropp JK, Zaman S, Melgar A, 2008: Effects of essential oils on in vitro ruminal fermentation and ammonia release. Animal Feed Science and Technology 144, 55-64.

Jarvis SC, Lovell RD, Panayides R, 1995: Patterns of methane emissions from excreta of grazing animals. Soil Biol Biochem, 27 (12): 1581-1588.

Johnson DE, Hill TM, Ward GM, 1992: Methane emissions from cattle; global warming and management Issues, In Proc. Minnesota Nutr.Conf., Minnesota Ext.Serv., Univ. Minnesota, St Paul.

Kaçar D, 2008: Screening of some plant species for their total antioxidant and antimicrobial activities. Master thesis, İzmir Institude of Technology, i̇zmir.

Kamalak A, Canbolat O, Ozkan CO, Atalay Al, 2011: The effect of essential oil (Thymol) supplementation on in vitro gas production profiles and fermentation end products of alfalfa hay. Kafkas Univ Vet Fak Derg, 17(2): 211-216.
Kamalak A, Canbolat Ö, Gürbüz Y, Özay O, Erer M, Özkan ÇÖ, 2005: Kondanse Taninin Ruminant Hayvanlar Üzerindeki Etkileri Hakkında Bir İnceleme. KSÜ Fen ve Mühendislik Dergisi, 8(1): 132-137.

Macheboeuf D, Morgavi DP, Papon Y, Mousset JL, 2008: Arturo- Schaan M. Dose-response effects of essential oils on in vitro fermentation activity of the rumen microbial population. Anim Feed Sci Technol, $145,335-350$.

Makkar HPS, Blummel M, Becker K, 1995: Formation of complexes between polyvinyl pyrrolidones or polyethylene glycols and their implication in gas production and true digestibility in vitro techniques. Br J Nutr, 73, 897-913.

Markham R, 1942: Distillation apparatus suitable for microkjeldahl analysis. Biochem J, 36, 790.

Mcintosh FM, Williams P, Losa R, Wallace RJ, Beever DA, Newbold CJ, 2003: Effects of essential oil on rumenial microorganism and their protein metabolism. Appl Environ Microbiol, 69(8): 50115014.

Menke KH, Raab L, Salewski A, Steingass H, Fritz D, Schneider W, 1988: Estimation of the energetic feed value obtained from chemical analysis and in vitro gas production using rumen fluid. Animal Research Development, 28, 7-55.

Newbold CJ, McIntosh FM, Williams P, Losa R, Wallace RJ, 2004: Effect of a spesific blend of essential oil compounds on rumen fermantation. Anim Feed Sci Technol, 114, 105-112.

Newbold CJ, Wallace RJ, Watt ND, Richardson AJ, 1988: The effect of the novel ionophore tetronasin (ICI 139603) on ruminal microorganisms. Appl Environ Microbiol, 54, 544-547

Patra AK, Saxena J, 2009: Dietary phytochemicals as rumen modifiers: A review of the effects on microbial populations. Antonie Van Leeuwenhoek, 96, 363-375.

Radeleff RD,1970: Veterinary Toxicology. Philadelphia, Lea\&Febiger, 33.

Scalbert A, 1991: Antimicrobial properties of tanen. Phy tochemistry, 30, 3875-3883.

Silanikove N, Perevoltsky A, Provenza FD, 2001: Use of tannin-binding chemicals to assay for tannins and their negative postingestive effects in ruminants. Animal Feed Science and Technology, 91, 69-81.

SPSS, 2004: Windows User's Guide. Version 13.0, SPSS Inc., Michigan Ave., Illinois, USA., Chicago.

Şener S, Yıldırım M, 2000: Veteriner Toksikoloji. Teknik Yayıncılık, 221-223.

Tamminga S, 1996: A review on environmental impacts of nutritional strategies in ruminants. J Anim Sci, 74, 3112-3124.

Thornton JH, Owens FN, 1981: Monensin supplementation and in vitro methane production by steers. Journal of Animal Science, 52, 628-634.

Van Soest PJ, Robertson JB, Lewis BA, 1991: Methods for dietary fiber, Neutral detergent fiber and nonstarch polysaccharides in relation to animal nutrition. $J$ Dairy Sci, 74, 3583-3597. 
Waghorn GC, 2008: Beneficial and detrimental effects of dietary condensed tannins for sustainable sheep and goat production-progress and challenges. Anim Feed Sci Technol, 147, 116-139.

Wallace RJ, McEwan NR, Mclntosh M, Teferedegne B, Newbold CJ, 2002: Natural products as manipulators of rumen fermentation. Asian-Aust $J$ Anim Sci, 15(10): 1458-1468.

Yost WM, Young JW, Schmidt SP, McGilliarg AD, 1977: Gluconeogenesis in ruminants: Propionic acid production from a high-grain diet fed to cattle. Journal of Nutrition, 107, 2036-2043.
**Bu araştırma makalesi "Bazı kaba yemlere farklı seviyelerde ilave edilen söğüt ağacı (salix $a / b a$ ) yaprağının in vitro sindirim ve metan oluşumu üzerine etkisi" isimli yüksek lisans tezinden özetlenmiştir.

*Yazışma Adresi: Mehmet AVCI

Harran Üniversitesi, Veteriner Fakültesi, Hayvan Besleme ve Beslenme Hastalıkları Anabilim Dalı, Şanlıurfa, Türkiye e-mail: mavci@harran.edu.tr 